\title{
A discursive psychology analysis of emotional support for men with colorectal cancer
}

\begin{abstract}
Recent research into both masculinity and health, and the provision of social support for people with cancer has focussed upon the variations that may underlie broad assumptions about masculine health behaviour. The research reported here pursues this interest in variation by addressing the discursive properties of talk about emotional support, by men with colorectal cancer - an understudied group in the social support and cancer literature. Semi-structured interviews were conducted with eight men with colorectal cancer, and the transcripts analysed using an intensive discursive psychology approach. From this analysis two contrasting approaches to this group of men's framing of emotional support in the context of cancer are described. First, talk about cancer was positioned as incompatible with preferred masculine identities. Second, social contact that affirms personal relationships was given value, subject to constraints arising from discourses concerning appropriate emotional expression. These results are discussed with reference to both the extant research literature on masculinity and health, and their clinical implications, particularly the advice on social support given to older male cancer patients, their families and friends.
\end{abstract}

Keywords: social support; masculinity; qualitative research; men's health; colorectal neoplasms

\section{Introduction}

The effect of constructions of masculinity on men's health behaviour is of increasing interest within health psychology. At the same time in the UK a public health policy debate has 
developed about how health services should be tailored to the needs of men (Men's Health Forum, 2010). This interest has been prompted in part by the finding that men have poorer health outcomes than women across a number of significant diseases (Courtenay, 2000). It has been argued that constructions of masculinity - cultural concepts of how men think, feel and act - have real world effects by shaping distinctive patterns of men's health behaviour. These effects have been identified in areas such as attitudes to drug and alcohol consumption, physical activity and sexual behaviour (De Visser, et al., 2009; Mahalik, et al., 2007) and seeking medical help (Seymour-Smith, et al., 2002).

This literature has identified a broadly coherent set of health behaviours that might be constructed as 'masculine', and linked these to the familiar concept of hegemonic masculinity - a dominant approach to social relations and self-presentation of men that is shaped by notions such as independence, stoicism, strength, and competition (Coates, 2003). Connell and Messerschmidt (2005) have called for studies of masculinity to look beyond the idea of a single, hegemonic masculinity, and attend more to tensions and diversity within the phenomenon. This work has begun in health psychology. For example, De Visser et al. (2009) found male focus group participants endorsed some hegemonic masculine qualities whilst deviating from other standards of hegemonic masculinity. They suggest this contradiction is significant and argue that men can accrue masculinity 'capital' in some areas of health behaviour by adhering to norms of hegemonic masculinity - in their research this was physical prowess. This 'capital' can then be 'spent' by not following these norms in other areas - such as alcohol consumption. A similar pattern of contradiction emerges in interview studies of men who attend cancer self-help groups by Seymour-Smith (2008) and Gray et al. (2002). They describe how participants legitimated their membership of a group (which might be perceived as 'un-masculine') by distancing themselves from the notion that 
they attended in order to receive help for themselves. Instead, they justified their attendance in terms of helping others.

A high rate of psychological distress has been found in cancer sufferers (Zabora et al., 2001), and one important moderator of the level of distress experienced by cancer patients is thought to be the level of social support they receive from others. The apparent tension between constructions of masculinity and accepting social support, identified by Seymour-Smith (2008) and Gray et al (2002), poses a dilemma for the design of social support interventions designed to reduce the psychological distress experienced by some men with cancer. This dilemma might be thought to be particularly acute for one component of social support emotional support which is usually described as involving the disclosure of thoughts and emotions, the making of empathic comments, and conveying the sense that the person is valued and loved (eg. Dakof and Taylor, 1990; Helgeson and Cohen, 1996). Receiving such support would not seem to be consistent with several pillars of hegemonic masculinity such as strength, stoicism and independence. However, higher levels of emotional support have been found to correlate with lower levels of psychological distress, and improved psychological adjustment to illness, in varying cancer populations (Helgeson and Cohen, 1996). Mirroring this finding, perceived social constraints on talking about cancer with spouses or friends and family have been found to be associated with higher levels of distress in men with prostate cancer (Lepore \& Helgeson, 1998). Research findings such as these have influenced practice, and cancer patients and their friends and family can now access advice that encourages the provision of emotional support for people with cancer (Macmillan, 2011). 
The research described in this paper focuses upon the potential tension between uptake of emotional support and constructions of masculinity, experienced by men with colorectal cancer. Colorectal cancer is the third most common cancer in men in the UK. It is primarily a disease of older people with around $85 \%$ of cases occurring in people aged 60 or over (Cancer Research UK, 2010). Rates of psychological distress in sufferers of colorectal cancer are consistent with rates in cancer more generally (Zabora et al., 2001), although the disruption of a taken for granted bodily function associated with social taboos, through the use of stomas, has been argued to carry a particular challenge for sufferers (Little et al., 1998). This paper addresses potential gaps that have been identified in the related health psychology literature, such as how older men ‘do' gender (Emslie et al., 2004), and less researched cancer patient groups (Williams et al., 2004).

The study described here uses the methods and theoretical insights of discursive psychology. Discursive psychology has been applied to an increasing range of topics in health psychology (eg. Peel et al., 2005; Seymour-Smith, 2008; Wilkinson and Kitzinger, 2000) and lent itself to this study for two reasons. First, the construction of gender identities has been a particular interest of this approach. Second, the use of language in social interaction is its central concern. Language substantially constitutes and constrains the social interactions that convey emotional support, and from the perspective of discursive psychology also shapes the subjectivity of the people involved in such interactions (Harré and Gillett, 1994).

This study employs the synthetic approach to discursive psychology outlined by Margaret Wetherell and Nigel Edley (Edley, 2001; Wetherell, 1998; Wetherell and Edley, 1999). This approach combines the traditions of conversation analysis and ethnomethodology (Antaki \& Widdicombe, 1998; Edwards, 1997), and post-structuralist informed discourse analysis 
(Shapiro, 2001). From conversation analysis and ethnomethodology, the synthetic approach derives an attention to the specific and immediate functions of talk which might include persuading others or justifying oneself, or talking in a way that aligns one with a particular social identity. From post-structuralist discourse analysis the synthetic approach derives a concern with normative systems of sense-making. It attempts to identify how speakers use ideas that are influential in the wider historical, political, social and cultural context.

Edley (2001) describes three analytic concepts for use in this approach to discursive psychology. The first, interpretive repertoires, are collections of terms and metaphors that are drawn upon by speakers to make sense of events in the world. Interpretive repertoires represent the influence of normative systems of sense-making on talk. The second concept, ideological dilemmas (Billig et al., 1988), arises from the finding that many of the interpretive repertoires that we are able to draw upon as part of our everyday common sense are contradictory or dilemmatic. Billig et al. (1988) suggest that these contradictions are not accidental. Instead opposition between interpretive repertoires are necessary developments to enable thought and argument about the objects to which they refer. The third analytic concept, subject positions, connects the larger scale concepts of interpretive repertoires and ideological dilemmas to the local conversational context. Subject positions refer to the identities and conversational positions that are made possible by the use of particular interpretive repertoires. It follows from this that selves and identities are not considered fixed, but instead can be multiple and flexible, conjoured into being during particular social interchange (Antaki \& Widdicombe, 1998; Davies \& Harré, 1990).

These concepts informed the research question. What interpretive repertoires shape and constrain the talk, and action, of men with colorectal cancer in relation to emotional support? What forms of emotional support do these interpretive repertoires make possible and likely, 
or impossible and implausible? How do men with colorectal cancer draw upon these interpretive repertoires to claim particular identities?

Interviews with men with colorectal cancer, where possible including a partner or other member of their support network, were selected as the most effective method for gathering data to address these questions. Some researchers have highlighted significant advantages in the use of records of naturalistic talk, rather than talk derived from semi-structured in discursive psychology analyses (eg. Potter \& Hepburn, 2005). Whilst we accept the merit of many of these arguments, especially assuring those concerning the contrived nature of the data produced from interviews, we concluded that recording many examples of the kind of informal interaction amongst a social network that might constitute emotional support for this group 'as it happens' might be practically very difficult. Further there are good arguments for interviews as a means of gathering data for discursive psychology research including an opportunity for the researcher to engage with participants and use questions to explore the accounts they give of their lives (Griffin, 2007). Finally, participants were invited to nominate somebody who had been helpful to them during their cancer experience to join in the interview, to widen the conversational data available for analysis to include talk from potential providers of emotional support.

\section{Method}

The study received ethical approval from an NHS research ethics committee. Potential participants were contacted via two specialist regional cancer centres in the UK. Sixty men who had received surgical treatment for colorectal cancer between one and three years previously were sent a letter by their specialist colorectal nurse inviting them to participate. 
Only men whose cancer had not spread beyond the wall of their bowel were contacted in order to maintain some homogeneity of cancer experience. Fourteen men contacted the researcher to indicate their willingness to participate, although only eight, aged between 62 82 were eventually interviewed due to the limited time available to conduct interviews. Three men with colorectal cancer took the opportunity to be interviewed together with someone who had been helpful to them during their cancer experience. All three nominated their wives, and these participants were interviewed as couples

Written consent for participation and the use of anonymized transcripts for research was obtained before the interviews began. The interviews took place either in the participant's own home, or in a consulting room at a large acute hospital, and lasted between forty and ninety minutes. The interviews, transcription, and analysis were carried out by the lead author, a twenty-seven year old male trainee clinical psychologist. The impact of these researcher characteristics is visible in different aspects of the study. During interviews participants occasionally referred to a shared 'common sense' that they assumed the interviewer would carry. The interviewer has some insider access to notions of masculinity which impacts the analysis. The aim of the interviews was to facilitate talk on the topic of emotional support and cancer without leading the participant or participants (Smith, 1995).

The interviews were guided by the following schedule of four topics for discussion.

1. How was your cancer discovered and treated?

2. How have you have adapted to life after treatment for cancer?

3. Completion of a simple social network map listing the members of the participant's social network, and the support provided by these people during the participant's cancer experience. This was intended as an interview prompt, rather than to gather data for further analysis. 
4. Did you notice any changes in yourself or your relationships as a result of your experience of cancer?

Analysis of the data was carried out concurrently with the interviews. Further prompts were added to the interview schedule for later interviews to include salient issues that emerged in the analysis of earlier interviews.

The analysis followed the procedures for the synthetic approach to discursive psychology outlined by Edley (2001), and readers are directed there for a full account of the process. The interviews were transcribed in full. Transcription followed an abbreviated form of the Jeffersonian transcription system (Edley, 2001), described at the end of this paper. The analysis sought to identify recurring interpretive repertoires, ideological dilemmas and subject positions. Broadly the process began with familiarisation with transcripts, progressing to the extraction and organisation of sections of talk relating to emotional support into a file, and finishing with comparison of extracts to infer broader conclusions from the data. The process was iterative, and assisted by discussion of emerging ideas with other researchers.

To ensure transparency, the process of analysis and findings reported in the results section remain within the data extracts that are presented alongside them. Participants' names have been replaced with pseudonyms, but the name of the interviewer has been left unchanged.

\section{Results and Discussion}

Two clear emotional support themes were apparent in the data. Their presence was marked both by the frequency with which they occurred across interviews, and the detail in which 
they were talked about by participants. The first theme incorporates interpretive repertoires and subject positions that appear incompatible with the use of emotional support by men with colorectal cancer. By contrast, the second theme includes an interpretive repertoire that permits men to value particular forms of social contact during their illness. In the excerpts that follow the interviewer is denoted by 'Int.'

\section{The problem with drawing on emotional support}

This section presents examples of participants' talk that explained and justified why they didn't talk about their cancer. This was sometimes because of an apparent incompatibility between talking about cancer and other roles or personal qualities they considered significant, as in excerpts two, three and four. In the first extract, David and Pauline talk around his reasons for not realising the seriousness of cancer, before justifying 'making light' of the diagnosis for their children.

\section{Excerpt 1 - David and Pauline (interview 5)}

1 Int. Can you say what it was like for you in those just that time when you were between the diagnosis and the operation

3 David Well as I say it all happened very very quickly didn't it

4 Pauline Well you didn't sort of time to think about it to be quite honest=

5 David =No we sort of went straight through

6 Pauline We didn't like (.) we didn't we didn't like (.) it was as if it was like any other operation wasn't it? I know that sounds a bit whatsaname but it was=

8 David $=$ I don't think we realised the seriousness of it

9 Pauline No probably not 
David I think that was more of the more of it we didn't realise how serious the consequences could have been I knew it was a bad thing like but I think the way they explained it to me you know cos when he was telling me what they was doing he said 'Oh' you know he was sort of drawing diagrams and he was saying 'That's where it is now what we're gonna do we're just gonna chop it there chop it there and it's just a plumbing job to us we'll just chop out the bad bits throw it away join it back together and you'll be fine' and I think (.) by explaining it like that I think it took away the seriousness of what actually it was

David and Pauline then elaborate upon David's 'naiviety' about the potential seriousness of his cancer, before David introduces the issue of protecting his children from the seriousness of cancer on line 24 .

David I think there was naivety definitely on my part about=

Pauline $=$ There was no consciousness about anyway we felt (.) we actually just sailed through it to be quite honest we really did and there was nothing conscious about saying right I'm gonna fight it we didn't say that because at the end of the day what's gonna happen is gonna happen isn't it no matter what you do really you know

David I think I was I was probably more concerned about how my children were gonna react you know and I was more like 'Now look we know what it is= Pauline =It all sounds terrible David So be careful with the kids like now you know we've gotta treat them like really with kid gloves here cos I know that like me eldest son' you know I said 'oh I 
dread telling him cos I know he's gonna really go to pieces over it' you know so I said and I think we probably made light of it more for the kids' sake as well

Int. $\quad=$ oh right ok

David =you know that we didn't wanna say 'You know this is really serious'

This excerpt begins with David and Pauline using a series of brief conversational turns to construct an account of David as 'not realising the seriousness' of his cancer diagnosis and investigations. This construction is clearly a joint one with David and Pauline using their turns to confirm or elaborate the account given by the other. In line 5, David starts to use 'we' rather than 'I', thereby implying that the response to the diagnosis that they are both describing was a joint response, shared between Pauline and himself. Pauline echoes this use of 'we' throughout the rest of the excerpt, whilst David uses we and I inter-changeably. The early part of the excerpt can be seen as the gradual development of an account of David's 'naivity' to the potential seriousness of the diagnosis. David uses this term on line 18, although notably he restricts this to 'on my part'.

However, on line 24 David adjusts this construction of his position as naïve, by introducing his concern about his children's reaction to the diagnosis, suggesting a more sophisticated role for himself as both aware of the seriousness of the diagnosis, and able to screen this from his children. Pauline acknowledges the potential seriousness of a diagnosis of cancer in line 26. David describes planning how the news might be broken to his children (lines 27-28) and his prediction that his eldest son would be very distressed (line 29). David then summarises his and Pauline's response by saying that they made 'light' of the diagnosis for their children's sake (line 30). Pauline continues to use 'we' and helps develop David's account in her turns. 
A discursive psychology analysis of this extract suggests that David was able to shift his subject position from a naive cancer patient to being a protective parent. This new subject position of being a protective parent allowed David to present qualities of protectiveness towards others, whilst moving the conversation on from his own response to his diagnosis of cancer which had been focussed upon by the interviewer's question, and the earlier David and Pauline's response to the question. The topics and ideas David refers to when occupying this new subject position form an interpretive repertoire about the responsibilities of a parent. This repertoire includes discussion of children's likely responses to the diagnosis of cancer, and the justification of actions such as making 'light' of the diagnosis as being in the best interests of children. There is little scope in the repertoire for David to discuss his own responses, a feature that may overlap with repertoires associated with hegemonic masculinity, but in this case is the product of a separate repertoire that is shared by David's wife.

David's switch to a different subject position from that given to him by the question suggests a poor fit between talk about his own emotional support needs in the context of cancer and a preferred role and identity. The next excerpt, taken from an interview with Charles, provides more striking evidence of the way in which emotional talk about cancer jars with preferred masculine subject positions. The exchange followed a question the interviewer asked about whom Charles had told about his cancer diagnosis.

\section{Excerpt 2 - Charles (interview 3)}

1 Charles I didn't want the family (.) I didn't want the family (.) I just didn't want they probably worry more about that you know (.) when it's serious you know=

3 Int. $\quad=$ ok 
4 Charles =I didn't want them worried about me I don't want nobody worrying about me=

$5 \quad$ Int. $\quad=$ ok

6 Charles no (.) things like that I'll keep to myself in any case you know (laughter)

$7 \quad$ Int. $\quad=$ ok

$8 \quad$ Charles $=$ It's a well kept secret

Charles expresses his preference for not disclosing news of his diagnosis to his family, which he justifies by saying they would worry more than him (lines 1-2). Charles uses a similar interpretive repertoire to that used by David. In Charles' use this repertoire prioritises the responses of others to news of the cancer diagnosis and suggests one way of managing his family's worry about this news is to make it 'a well kept secret'. Marking a difference from David's account, Charles elaborates on the notion of a 'well kept secret' by asserting on line 4 that "I don't want nobody worrying about me". We argue that Charles is drawing upon a further interpretive repertoire that depicts sharing knowledge about his cancer as a threat to his autonomy and self-reliance, which are best preserved by secrecy. The conflict between sharing knowledge and autonomy has an either/or quality that suggests they form an ideological dilemma. By constructing worrying by others as acting against his own wishes, this repertoire positions Charles in conflict with those who would show concern at his illness. Charles forcefully articulates this interpretive repertoire of autonomy later on in the interview.

\section{Excerpt 3-Charles (interview 3)}

1 Int. So what kind of help would have been best for you just er

2 Charles Left alone (.)

3 Int. Being left alone

4 Charles Left alone yeah 
$5 \quad$ Int. Yeah

6 Charles If I needed help I would ask for it but if I didn't you know I'll just get on and do

7

it

$8 \quad$ Int. $\quad$ Ok

9 Charles That's me

Charles' use of the phrase 'left alone' (line 2) implies that offers of help would have been an unwelcome intrusion. Charles summarises his commitment to autonomy on line 6 with the phrase 'I'll just get on and do it (.) that's me.' We argue that this discursively constructed conflict makes participants less likely to engage in the kinds of interactions that would allow the provision of emotional support to them. Further, the explicit rejection of this kind of cancer talk enables participants to adopt subject positions that are associated with valued qualities such as being protective, self-reliant, and stoic. These positions resonate with contemporary accounts of hegemonic masculinity (Coates, 2003).

The autonomy interpretive repertoire is developed by Donald in the next extract. The extract arose in the context of a discussion about who one can talk to about cancer, with particular reference to Donald's friends in a local social club. Unlike Charles and David, Donald does not refer to a personal preference as the reason for being careful about discussing illness, but instead he refers to a social taboo about illness talk.

\section{Excerpt 4 - Donald (interview 2)}

1 Donald $\underline{\text { Ahh }}$ we had a chat in the club

2 Int. Right 
Donald You know (.) but er (.) you don't (.) you don't tell people personal things do you you know (.)

Int. Yes

Donald But you listen you think 'Oh' a chap might say 'I had that and I got over it' you know I mean I didn't know but there was a chap in my club and er I was talking to him the other week and he said 'How you going Donald' I said 'Alright (.) can't grumble' and er (.) we got chatting and he said 'Oh I had cancer like you' (.) now I never knew =and I've known the chap years]

Int. =you never knew that he (.) right ok

Donald And er we got chatting he said 'I had that years ago'

Int. Oh yeah

Donald And I said 'Bloody hell' I said 'You got over it then' he said 'Yeah and you have' (.) I said 'Yeah' I said ‘And there's a lot of bloody moaners in here you know (.) moaning about it' I said er (.) 'You wanna go and see the doctor' [yeah] (.) but er

Int. So how how did he know about your cancer

Int. Talking ok

Donald Cos I said to him like we was talking having a drink and I said 'Of course I had cancer you know and I've done very well' and he said 'Oh I I had cancer'

Int. But you say that it's er it's a private thing

Donald Yeah

Int. Yeah so (.) something you wouldn't normally talk to people about

Donald Not really do you tell me your illnesses (laughter)

Int. No 

your bank balance? Do you tell anybody else? (laughter) course you don’t (.) it's the same (.) same predicament isn't it you don't wanna know your worries and I don't want to know yours you've got enough

Int. $\quad \mathrm{Ok}$

Donald And I've got enough $=$

Int. $\quad=$ Yeah

In this extract Donald begins on lines 3-6 by making a distinction between 'telling people personal things' which he says you 'don't do' and a more nuanced approach to discussion of illness. He begins his description of this nuanced approach by saying 'you listen', and then gives an example of how, by listening, he ended up discussing his cancer experience with another member of his club. However, following an intervention by the interviewer clarifying the potential inconsistency of discussing his cancer, Donald responds by strongly arguing that illness should not be talked about to others. Donald does not engage with the interviewer's question directly, and certainly does not support the interviewer's suggestion of inconsistency. Instead he reverts to explaining why it is not possible to talk about illness using devices such as rhetorical questions and an appeal to the interviewer's own experience on line 28 'do you tell your friends illness do they tell you?' that seem to refer to a shared common sense, but also indicate the role of the male interviewer and interview context in coproducing this particular account as Donald attempts to align his account with what he perceives the interviewer would do. Donald's laughter on lines 26 and 35 suggests that to behave in any other way would be absurd. In short this perspective has the properties of an interpretive repertoire that depicts speaking about one's illness as socially inappropriate and 
therefore creates a norm out of self-reliance and reticence about illness. On line 15 Donald uses the phrase 'moaners' to describe people in his club who talk about their illnesses 'there's a lot of bloody moaners in here you know'. On line 8-9 he recounts that he said he was 'Alright (.) can’t grumble'. Thus Donald literally exposes the limits imposed by this interpretive repertoire upon what he ought to say about his health and well-being.

In drawing upon this interpretive repertoire of socially appropriate illness talk, Donald is able to position himself apart from grumblers and moaners. In so doing he can be seen as being self-reliant, like Charles, but also being stoic, bearing his illness, without complaint to others. Whilst Donald's most emphatic passage of talk in this excerpt, partly in response to a challenge from the interviewer, concerns not telling people personal things, the excerpt also includes an account of how illness might be talked about. This is expressed in the form of an anecdote on lines 21-22 'I said 'Of course I had cancer and I've done very well'’. This repertoire doesn't have such strong ideological properties, but hints at ways in which cancer might discussed - in the past tense rather than as a current concern, in response to listening to others rather than a more direct disclosure oneself.

The excerpts discussed so far have illustrated a variety of ways in which the sharing of news about cancer, presumably a prerequisite for the receipt of emotional support, was problematized or rejected by participants. This pattern also appears in the excerpts presented in the next section, which also illustrate more positive constructions of emotional support during cancer.

\section{Valuing personal relationships, devaluing emotion.}


This section presents excerpts of talk that concern the emotional benefits of social interaction relating to cancer. In excerpt five Paul recounts being 'touched' by a visit from his children to see him in hospital. Paul moderates the sentimental subject position that might be implied by this disclosure by using humour.

\section{Excerpt 5 - 'Paul' (interview 1)}

Paul (.) although you're always touched the my I've got two they don't live here in \{city name\} I mean we don't see them well we do I suppose but they don't spend every weekend here so you get a bit touched when you're there in hospital and they suddenly all appear and you think 'Oh God do they think I'm going to die or something?' (laughter) the daughter turns up the son then both coming within a short time I'm not used to such normally we see them in drips and drabs

Paul continues with this theme, shortly afterwards.

Paul's talk is similar to the making 'light' of the situation described by David in the first extract in this paper. Paul describes being 'touched' (line 1) by his children coming to see him in hospital. He therefore constructs the visit as welcome, but also indicates a potential problem by using the phrase 'Oh God do they think I'm going to die or something'. Paul then laughs. He leaves unsaid whether, for him, the problem is with his own risk of mortality, or witnessing his children's perception of this. Paul's elaboration of this theme 
later on repeats both aspects. He again uses the phrase 'Oh God' to indicate he constructs having to talk to a 'family discussion (.) snuff it or something' as problematic, before laughing. As with the construction 'Oh God', Pauls' laughter is indicative of awkwardness concerning either the family discussion, or his mortality, or both. The use of these devices indicates to the interviewer that the contact with his family is both welcome and troubling to Paul, and adjusts his subject position from a more straightforward gratitude for support, to a mixed response to the contact with his family.

The next excerpt contains a further example of an accommodation between talk about valuing social contact during the cancer experience and a demonstration that the speakers, in this case a husband and wife, are not comfortable with too much emotional expression.

\section{Excerpt 6-David and Pauline (interview 5)}

Pauline we had loads of support loads of er and people said 'I'll take you if you're going up tonight I'll take you and I'll' you know yeah loads of people mm

David Even customers off me taxi phoned me up like you know and er other drivers phoned me up =you know

Pauline =yeah

Pauline And and you take like three $=u m$

David =special needs children

Pauline special needs children to school

Int. Oh right

Pauline And their parents they all sent you a =card

David =they all yeah 
Pauline Yeah we had a house full of cards and everything yeah no people were really really nice

David: really supportive

Pauline without (.) cos you don't (.) =you don't want you want you don't want too much ((inaudible))]

David =Without being over dramatic I know who she means but this= particular person she gets over dramatic over anything like you know so

Pauline Yeah I can't handle that kind of thing you know

Int. yeah $=$

Int. Yeah

Pauline You know in doing things like you know um some some people get a bit more emotional than others I know

Pauline and David begin by referring to receiving 'loads of support' (line 1) from apparently surprising sources 'even customers off me taxi phoned me up' (lines 3-4). On lines 12-13 Pauline says 'people were really really nice.' However this apparent valuing of support from others quickly gives rise to the ideological dilemma already described. Pauline is the first to try to accommodate the dilemma, by pointing out on line 15 that 'you don't want too much' emotion. David then supports what Pauline has said. Pauline then says that most people are 'quite sensible' (line 21), as opposed to others who 'get a bit more emotional' (lines 23-4). Here Pauline seems to be appealing to an interpretive repertoire that she assumes is shared and does not need to be fully explained. Using the notion of being sensible Pauline and David achieve the same ends achieved by Paul's use of humour in the previous extract. An 
accommodation is found between valuing social contact and maintaining a subject position that excludes too much emotional expression or the impression of sentimentality.

This finding is consistent with other research into British men's talk that finds side by side sociability is valued, rather than intimacy (Coates, 2003), and that men's identities are troubled by emotion talk (Seymour-Smith , 2008). However, this data does not support a simple gender division. In extract six, it is Pauline who takes the lead in co-constructing her account with her husband, David. Furthermore Pauline doesn't explicitly confine her statements about norms to men only. In fact none of the participants in the excerpts reported here explicitly refer to masculinity or gender as an explanation for the approaches to seeking emotional support during cancer that they described. However, we argue that the interpretation of this data as reflecting masculinity can still be sustained given the consistency between accounts of different men within this research and with other accounts of masculinity. Nevertheless, it is striking that the lens of masculinity was not one that participants spontaneously oriented to, and that this research identified potentially overlapping interpretive repertoires and subject positions, not exclusively masculine, that might make emotional support during cancer problematic.

\section{Conclusion}

The talk of older men with colorectal cancer reported here lends support to Connell and Messerchmidt's (2005) argument that the influence of constructions of masculinity is best understood as a sphere of diverse and sometimes countervailing forces. Most participants appeared to reproduce pillars of an historically, politically, socially and culturally determined hegemonic masculinity that positions emotion as troubling to men's identities, values side by side sociability above intimacy, and promotes self-reliance. This echoes findings from other 
contemporary research on the talk of British men (eg. ; Coates, 2003; Seymour-Smith, 2008) and extends its reach to older men.

However this apparent regulatory effect of hegemonic masculinity presented a dilemma to some participants who often did not wish to reject social contact out of hand. This dilemma also faces organisations concerned with the psychological well-being of men with colorectal cancer, and cancer more widely. If men are encouraged to talk openly about their cancer and associated emotions, this may run counter to their preferred identity positions and to the wider discursive currents that influence them. This design of study cannot arbitrate upon the question of whether participants who positioned themselves against disclosing conversations about cancer were psychologically worse off as a result. However, it is important to note that certain benefits of this approach might be inferred from the accounts given by participants themselves. In using these interpretive repertoires men were performing and reproducing historically and culturally sanctioned roles in being protective, emotionally resilient, selfreliant and stoic.

The findings suggest ingredients for a flexible model of emotional support for British men with colorectal cancer, that works with the grain of hegemonic masculinity. This would be consistent with a well established tradition in social support focussed on appropriate 'matching' of support to particular needs (Cutrona \& Russell, 1990). Interactions that affirmed personal relationships without breaching social constraints about the appropriate amount of emotional content were constructed as emotionally valuable to participants. Social support interventions such as advice leaflets and support groups for men with colorectal cancer might benefit from incorporating these specific findings. In particular, they might usefully emphasize that whilst creating opportunities for talking about cancer is important, it 
may be very important to have social contact that is not either directly or implicitly about cancer. However explicitly labelling advice as 'for men' would appear to be unlikely to be helpful. Participants in this study did not construct their experiences explicitly on gender lines.

Any attempt to generalise and apply these findings should be qualified by an appreciation of the limitations of this study. The very fact that only a quarter of men contacted about the study indicated an interest in participating suggests that the participants may respond differently to the notion of talk about emotional support and cancer from the majority of their peers. Interviews are imprecise analogues for cancer talk as it might happen in the day to day lives of men with colorectal cancer. For all participants a research interview was an unfamiliar conversational format. Furthermore, the young male Trainee Clinical Psychologist interviewer was also an unusual audience for the participants. In encountering this situation participants may well have drawn upon interpretive repertoires, and adopted subject positions, that were not typical of their behaviour beyond the interview. These possible caveats should be tempered by the knowledge that the findings are broadly consistent with findings from the small number of similar studies completed with British male cancer patients (eg. Seale, 2002; Seymour-Smith, 2008) and it remains our contention that the discursive resources evident in this study are likely to be reproduced in the interpersonal conduct of participants outside the interview.

Appendix: Transcription guide, adapted from Edley (2001).

(.) Short untimed pause

$=\quad$ Brief interjection by named speaker, or overlapping talk 
italic Word(s) emphasized

(laughter) Laughter

\section{References}

Antaki C and Widdicombe S (1998) Identity as an Achievement and as a Tool. In: Antaki C and Widdicombe S (eds) Identities in talk. London: Sage, 1-14.

Billig M, Condor S, Edwards D, Gane M and Middleton D (1988) Ideological Dilemmas: A Social Psychology of Everyday Thinking. Sage: London.

Cancer Research UK. (2010). High Risk Groups for Bowel Cancer. Available at www.cancerhelp.org.uk/type/bowel-cancer/about/risks/high-risk-groups-for-bowelcancer\#incidence

Coates J (2003) Men Talk: Stories in the Making of Masculinities. Oxford: Blackwell.

Connell RW and Messerschmidt JW (2005) Hegemonic Masculinity: Rethinking the Concept. Gender \& Society, 19(6): 829-859.

Courtenay WH (2000) Constructions of masculinity and their influence on men's well-being: a theory of gender and health. Social Science \& Medicine, 50: 1385-1401. 
Cutrona CE and Russell DW (1990) Type of Social Support and Specific Stress: Toward a Theory of Optimal Matching. In: Sarason BR, Sarason IG, and Pierce GR (eds) Social Support: An Interactional View. New York: Wiley, 319-366.

Dakof GA and Taylor SE (1990) Victims' Perceptions of Social Support: What is Helpful From Whom? Journal of Personality and Social Psychology, 58: 80-89.

Davies B and Harré R (1990) Positioning: The Discursive Production of Selves. Journal for the Theory of Social Behaviour, 20, 43-63.

De Visser RO, Smith JA and McDonnell EJ (2009) 'That's not masculine': Masculine Capital and Health-related Behaviour. Journal of Health Psychology, 14(7): 10471058.

Edley N (2001) Analysing Masculinity: Interpretive Repertoires, Ideological Dilemmas and Subject Positions. In: Wetherell M, Taylor S, and Yates SJ (eds) Discourse as Data: A Guide for Analysis. Milton Keynes: Open University, 189-228.

Edwards D (1997) Discourse and Cognition. London: Sage.

Emslie C, Hunt K and O’Brien R. (2004). Masculinities in Older Men: A Qualitative Study in the West of Scotland. The Journal of Men's Studies, 12(3): 207-226. 
Gray RE, Fitch MI, Fergus KD, Mykhalovskiy E, and Church K (2002) Hegemonic Masculinity and the Experience of Prostate Cancer: A Narrative Approach. Journal of Aging and Identity, 7(1): 43-62.

Griffin C (2007) Being dead and being there: research interview, sharing hand cream and the preference for analysing 'naturally occurring data'. Discourse Studies, 9, 246-269.

Harré R and Gillett G (1994) The Discursive Mind. London: Sage.

Helgeson VS and Cohen S (1996) Social Support and Adjustment to Cancer: Reconciling Descriptive, Correlational and Intervention Research. Health Psychology, 15: 135148.

Lepore S and Helgeson VS (1998) Social Constraints, Intrusive Thoughts, and Mental Health After Prostate cancer. Journal of Social and Clinical Psychology, 17(1), 89-106.

Little S, Jordens CFC, Paul K, Montgomery K, and Philipson B (1998) Liminality: A Major Category of the Experience of Cancer Illness. Social Science and Medicine, 47(10), 1485-1494.

Macmillan Cancer Support (2011) Why Talk? Why Listen? Available from www.macmillan.org.uk/Cancerinformation/Ifsomeoneelsehascancer/Talkingtosomeon e/WhytalkWhylisten.aspx 
Mahalik JR, Burns SM, and Syzdek M (2007) Masculinity and perceived normative health behaviours as predictors of men's health behaviours. Social Science and Medicine, 64: 2201-2209.

Men's Health Forum. (2010). MHF's Challenges to the NHS and Government. Available from www.menshealthforum.org.uk/improving-health-services/20199-mhfschallenges-nhs-and-government

Peel E, Parry O, Douglas M, and Lawton J. (2005). Taking the Biscuit? A discursive Approach to Managing Diet in Type 2 Diabetes. Journal of Health Psychology, 10(6): 779-791.

Potter J and Hepburn A (2005) Qualitative Interviews in Psychology: Problems and Possibilities. Qualitative Research in Psychology, 2, 38-55.

Seale C. (2002). Cancer Heroics: A Study of News Reports with Particular Reference to Gender. Sociology, 36: 107-126.

Seymour-Smith S, Wetherell M, and Phoenix A (2002) “My Wife Ordered Me to Come!” A Discursive Analysis of Doctors' and Nurses' Accounts of Men's Use of General Practitioners. Journal of Health Psychology, 7: 253-67.

Seymour-Smith S (2008) ‘Blokes Don't Like That Sort of Thing’: Men's Negotiation of a 'Troubled' Self-help Group Identity. Journal of Health Psychology, 13(6): 785-797. 
Shapiro M (2001) Textualizing Global Politics. In: Wetherell M, Taylor S, and Yates, SJ (eds) Discourse Theory and Practice: A Reader. Milton Keynes: Open University, 318-344.

Smith JA (1995) Semi-Structured Interviewing and Qualitative Analysis. In: Smith JA, Harré R, and Van Langenhove L (eds) Rethinking Methods In Psychology. London: Sage, 926.

Wetherell M (1998) Positioning and interpretative repertoires: conversation analysis and post-structuralism in dialogue. Discourse and Society, 9(3): 387-412.

Wetherell M and Edley N (1999) Negotiating Hegemonic Masculinity: Imaginary Positions and Psycho-Discursive Practices. Feminism and Psychology, 9(3): 335-356.

Wilkinson S and Kitzinger C (2000) Thinking differently about thinking positive: a discursive approach to cancer patient's talk. Social Science and Medicine, 50: 797811.

Williams P, Barclay L, and Schmied V (2004) Defining social support in context: a necessary step to improving research, intervention and practice. Qualitative Health Research, 14(7): 942-960.

Zabora J, Brintzenhofeszoc K, Curbow B, Hooker C, and Piantadosi S. (2001) The Prevalence of Psychological Distress by Cancer Site. Psycho-Oncology, 10: 19-28. 
